\title{
The Song Remains the Same...or Not? A Pragmatic Approach to the Lyrics of Rock Music ${ }^{1}$
}

\author{
Angelina Sophiadi \\ Aristotle University of Thessaloniki \\ asophiadi@gmail.com
}

\section{Abstract}

This paper explores how the lyrics of popular rock music associate with change as it is imprinted in language. More specifically, it aims to investigate the lyrics from a pragmatic perspective and to discern a possible fluctuation of certain pragmatic features (deixis, politeness strategies and, to some extent, speech acts) through time. Subsequently, it examines whether there is a connection between this fluctuation and ordinary language use. The research involves a preliminary questionnaire, and the use of a concordances program, which is employed for the processing of the lyrics of 225 songs.

\section{Introduction}

Popular music constitutes an integral part of the wider realm of popular culture and, since it operates within the social context, one can assume that the language employed in it, constitutes a "form of social practice" (Fairclough 2001: 18). Rock music, in particular, has been the dominant music genre² in consumer popularity

1 This paper constitutes a condensed version of my MA thesis submitted in the Department of Theoretical and Applied Linguistics in the School of English of the Aristotle University of Thessaloniki. The thesis was supervised by Dr. Eliza Koutoupi-Kitis, to whom I am thankful and grateful for her constant support and guidance. Of course, I am responsible for all mistakes and obscurities.

2 See http://76.74.24.142/8EF388DA-8FD3-7A4E-C208-CDF1ADE8B179.pdf for the RIIA 2008 ten year demographic survey on consumer profiles, http://www.riaa.com/newsitem. php?id=370FD0E5-4FCF-0724-8AEC-277A1D52A260 for the RIIA 1996 ten year trend data demographic survey on consumer preferences and http://www.bpi.co.uk/music-business/article/ the-market.aspx for information on the British market from the British Recorded Music Industry.

\section{(c)) BY-NC-ND}


for many decades and it "has been a crucial element in several youth culture movements" (Rutten 1993: 38) from the 1960 s to the present. Having a life-span of more than half a century, rock music has operated as a versatile force and has evolved into a resilient genre of popular music, incorporating all the good, and being the scapegoat ${ }^{3}$ for all the bad aspects of it.

\section{Anybody Listening? Lyrics as the Subject of Analysis}

In spite of their standardized nature ${ }^{4}$, there is a diversity of foci one can take on when studying lyrics. These range from content analysis and the connection between shifts in lyrics and changes in the socio-economic conditions (Mooney 1954; Pettijohn \& Sacco 2009), politics (Grossberg 1993; Frith 1993), how lyrics lead to the deviant behavior of youth (Knobloch-Westerwick et al. 2008; Robinson et al. 1996) to even language teaching (Kimbel \& Protivnak, 2010; Paquette \& Rieg, 2008).

Moreover, a considerable amount of research has been conducted within the domain of sociolinguistics regarding code switching between the African American Vernacular English and the respective standard language in the lyrics of rap music around the world ${ }^{5}$. Kuhn in 1999 attempts a pragmatic ${ }^{6}$ approach to the analysis of persuasive strategies in blues lyrics, employing speech act theory and politeness theory. She observes that there is common ground in songwriters in their attempt to mitigate the face-threatening act of a request, by means of redressive action in the form of positive-and negative politeness (Kuhn 1999: 528-533).

3 See http://www.slate.com/id/1008314/, http://www.snopes.com/rumors/radio.asp and http://en.wikipedia.org/wiki/List_of_songs_deemed_inappropriate_by_Clear_Channel_ following_the_September_11,_2001_attacks and for further information on the controversial 2001 Clear Channel memorandum regarding lyrically questionable -mainly rock- songs which radio stations had to avoid playing on air, following the September 11, 2001 attacks.

4 The notion of standardization, which "aims at standard reactions" (Adorno [1941] 2002: 442) by the listeners, and that of pseudo-individualism, which offers the illusion of free choice (ibid, 445), are central to Adorno's overview on popular music, concluding that this industry "provides trademarks of identification for differentiating between the actually undifferentiated" (ibid, 446).

5 Just to name a few, Androutsopoulos \& Scholz (2002), who deal with European rap music, and Pennycook (2003), who discusses code switching in the rap music of Malaysia, Japan, Korea and Pacific Rim countries, New Zealand, Fiji and Samoa.

6 Kuhn's research is quite well structured, although a bit small-scale (she only examines five songs). Her references however, reveal the scarcity of literature combining linguistics and popular music. 


\section{Methodologyand Research-TheQuestionnaire}

The research was initiated with a preliminary questionnaire ${ }^{7}$ to investigate the hypothesis that lyrics are noticed by listeners. The questionnaire was created with the use of an online survey software called Survey Monkey.

Nine closed questions and one open-ended question ${ }^{8}$ were constructed. The goal was to make it quick and easy to fill in, without getting into complex details. The processed questionnaires were those filled in online during a two-month period (April - June 2010).

The total number of participants was 185 and they represented different age groups and nationalities. The results regarding the music genre preference place rock music in the first position [71,9\%], which becomes even higher when taking into account the fact that $14,5 \%$ of the participants who actually selected the other option, mentioned subgenres of rock music like hard or progressive rock and heavy metal. The overwhelming majority of the participants [88\%] listens to music very often or always. In the question concerning whether they pay attention to the lyrics of songs, a safe percentage of $78 \%$ validates the presupposition.

Almost $60 \%$ of the participants answered that the lyrics of a song can affect their preference towards it, which could be an indication that lyrics play a role in the popularity of a given song. However, this percentage displays a decrease [37\%] when the subjects were asked whether they relate to the lyrics of the songs they listen to; popularity may not be a matter of self-expression, but rather a matter of taste or preference.

\section{Methodology and Research - Interrogating the Corpus}

After securing support for the assumption that listeners do pay attention to the lyrics, the next stage was to compile the corpus using a concordances program. AntConc 3.2.1 was selected, especially because of its simple and "well-structured [...] user interface" (Wiehman \& Fuhs 2006: 118).

The aim was to collect the same number of popular rock songs for each decade from the 1960 s up to the 2000 s. Whatever information was available was employed

7 See http://www.surveymonkey.com/s/5K78WDY for the online version of the questionnaire.

$\mathbf{8}$ In this question, participants were asked to quote an example of lyrics that they relate to. It was optional and included for future research. 
and crosschecked with other sources regarding sales and overall reception of music production, as well as official and unofficial chart collections ${ }^{9}$ for most European countries. Other parts of the music industry such as the Grammy awards, music television networks and magazines had to be taken into account as well.

Bearing all this in mind, ${ }^{10}$ five lists were created, one for each decade consisting of 25 rock songs each. The same procedure was followed for pop music, collecting, however, a slightly smaller sample of 20 songs for each decade. This discrimination was allowed for two reasons; first, the differentiation between rock and pop was a secondary hypothesis and, given the time, it was considered reasonable to have a smaller sample. The second reason had to do with the general genre of pop music and the range of subgenres it includes, or has come to include, over the years. Questions like whether dance music or rap music actually comprise pop music inevitably came up. Half a century ago, there was no such thing as rap music, which can be thought of as a separate genre, but in some cases it may be considered to be pop, as official charts show.

\section{Interrogating the Corpus - Results}

There were some revealing results in the samples regarding a specific pair of personal pronouns, namely I and you; the emergence of this pair, along with the constant presence of the third person, seems not to be arbitrary, considering Singer's analysis of Peirce's first, second and third person as "the underlying structures of communication and signification which form and express the semiotic self" (1989: 242). This tripartition is conspicuous in the lyrics throughout the decades with the three parts -first, second and third person- always dominating the first three positions in the frequency order. Their omnipresence is important since it indicates that, quantitatively speaking, the main focus on lyrics has to do with the communication and the signification of the self. Even without fluctuations in the frequency of occurrences, their mere dominance would still verify that lyrics follow the same structure of human interaction and communication since, their use constitutes "a condition for the formation of selves and person" (Singer 1989: 284).

9 www.billboard.com and www.billboard.biz for the official charts for all over the world. www.billboard.com/specials/hot100/index.shtml for various official top 100 lists during the years 1958-2008. http://www.theofficialcharts.com/music-charts/ the official UK charts website and www.vinylsurrender.com, an unofficial site containing many charts based both on visitors' vote and on official data and charts

10 One last thing one had to consider when compiling the corpus of song lyrics was to try to find artists or groups who were of diverse nationalities. For a list of the songs employed in all corpora, please contact me via e-mail. 


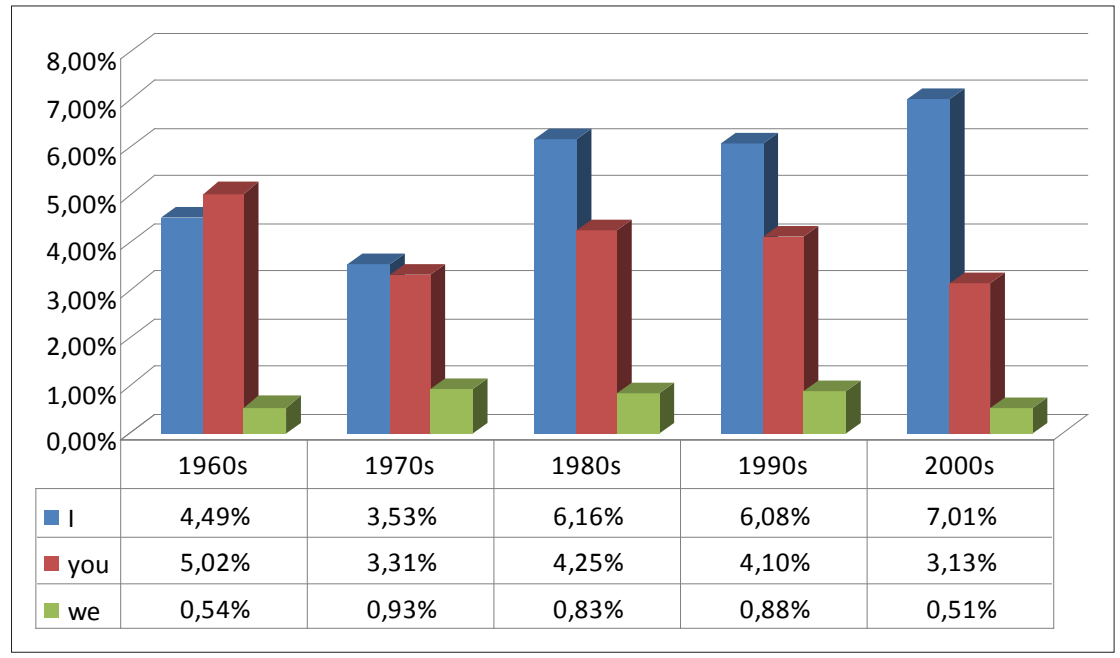

Figure $\mathbf{1}^{11}$. Percentages of the appearances of 'l', 'you', and 'we' in Rock music.

But apart from this, a fluctuation was observed between the occurrences of the first and the second person singular pronouns. The observed pairing of these two is also not random, since they are entirely indexical in terms of their reference, which makes them more easily relatable by the audience. When there is no referential restriction, one can interpret these pronouns in any way one wishes and this can be considered to be a popularity factor as far as song lyrics are concerned.

Observing the occurrences of the two pronouns diachronically, the shift from you to $I$ is prominent: the first person pronoun doubles the percentage of its appearance, whereas the second person singular pronoun ends up in the $2000 \mathrm{~s}$ having almost half the appearances it had in the 1960 s.

It is also of importance, however, to notice the difference in the order of their occurrences. During the 1960 s the most frequently occurring word in the lyrics

11 The first person plural pronoun is also mentioned in the tables above but not commented on. This is because, before even embarking on this research, one had the firm assumption that there would be expressions of solidarity or absence of it fluctuating through time in rock music, mainly by means of employing the inclusive and exclusive we. The results however, showed very little fluctuation. Also, we holds a very low position in the order of frequency in both corpora, leading one to assume that expressing solidarity -as its main function- is not of high significance for either genre. Considering however specific subgenres of rock or any other music for that matter, the results would have probably been different and one might anticipate a more prominent expression of inclusiveness and exclusiveness in the lyrics. 
was the second person pronoun you and the second -by a slight difference- was the first person I. This tuistical ${ }^{12}$ dominance quickly changes and in the $1970 \mathrm{~s}$ the order is reversed, displaying an egotistical trend. Gradually, the gap between the frequency of occurrences of the two pronouns becomes more prominent, as in the 1980 s the first person has 384 occurrences, whereas the second person has 265 occurrences, and in the 1990 s 418 and 282 respectively. In the sample of lyrics collected for the 2000 s the second person pronoun drops even more in terms of frequency with 201 occurrences, whereas the first person pronoun remains dominant with 449 occurrences.

Since the selection of the songs was based on criteria that had to do with their appeal, we cannot assume that this variation is random. If we consider music to be a type of media discourse relating to the discourse of those to whom it appeals, it is expected and well justified that these two pronouns were the most prominent ones in terms of frequency, exactly because their reference is indeterminate and, therefore, adaptable to the hearer's/interpreter's subjectivity or circumstances. This is a clear case of what one might call 'reference adaptability' of indexicality, a prevalent phenomenon in the genre of poetry. The tendency, however, towards the first person combined with the decline in the occurrences of the second person, opens the ground for additional inferences.

Lyons states that the deictic context of an utterance "is centered upon the speaker's here and now: it is, in this respect, egocentric" (1981: 305). In the case of the lyrics however, the egocentricity of the deictic context is even more prominent due to the gradual dominance of the first person singular pronoun. This is enhanced when taking into account that you has a generic use as well, replacing the indefinite one in more informal contexts (Quirk et al. 1972: 222). Also, the first person singular pronoun I can only be a subject whereas the second person you can operate either as a subject or an object. Fowler points out that it is characteristic of media discourse, to position as subjects people of authority, whereas "those with less power occur as objects" (1991: 98). Based on this suggestion, we could infer that the dominance of the first person singular may reflect a gradual ascension of the speaker/singer to a dominant position in relation to his 'addressee'. In other words, we witness a gradual shift of emphasis on the performer. As the you of the lyrics denotes the addressee of the singer's narrative or a secondary character of the discourse enacted, that is, the narrative of the song, but not the actual physical recipient of the song, the latter is expected to identify with the performer as the main agent of the narrative rather than with secondary characters of the narrative (you).

12 This term, along with egotistical and idistical as used to refer to the second, first and third person respectively, that will be used further on, is taken from Singer (1989: 239). 
Therefore, the focus is undoubtedly on the self, that is, the I. And this discourse of the self is quite reminiscent of recent work of psychologists, claiming that the current generation is more egocentric than the previous ones, "a generation unapologetically focused on the individual" (Twenge 2007: 2). This can be explained on the basis of the globalization experienced by every society, along with the commodification of almost everything: "In a society awash with flashy commodities [...] our language for representing [...] our image of self-identity is more and more fixed into a syntax of possession [and] ownership" (Elliot and Lemert, 2006: 41). This, of course, does not necessarily imply that people are becoming more selfish, for this would be a naïve assumption to make. The language employed in this genre in general, being the most popular one, could be indicative of a relative trend in the ordinary use of language; but this is something that has to be verified by means of historical linguistics, to see whether there is indeed a shift in the frequency of use of personal pronouns.

In pop music on the other hand, the results were slightly different. It looks like pop music, by and large, follows the pronominal patterns of rock music, only in more subtle ways. This may be attributed to genre differences between rock and pop music, or to the fact that -without any intention of standardizing pop music- the latter is more or less, thematically restricted to love and sexuality, and probably this restriction is translated into language that is not fully representative of its time of production.

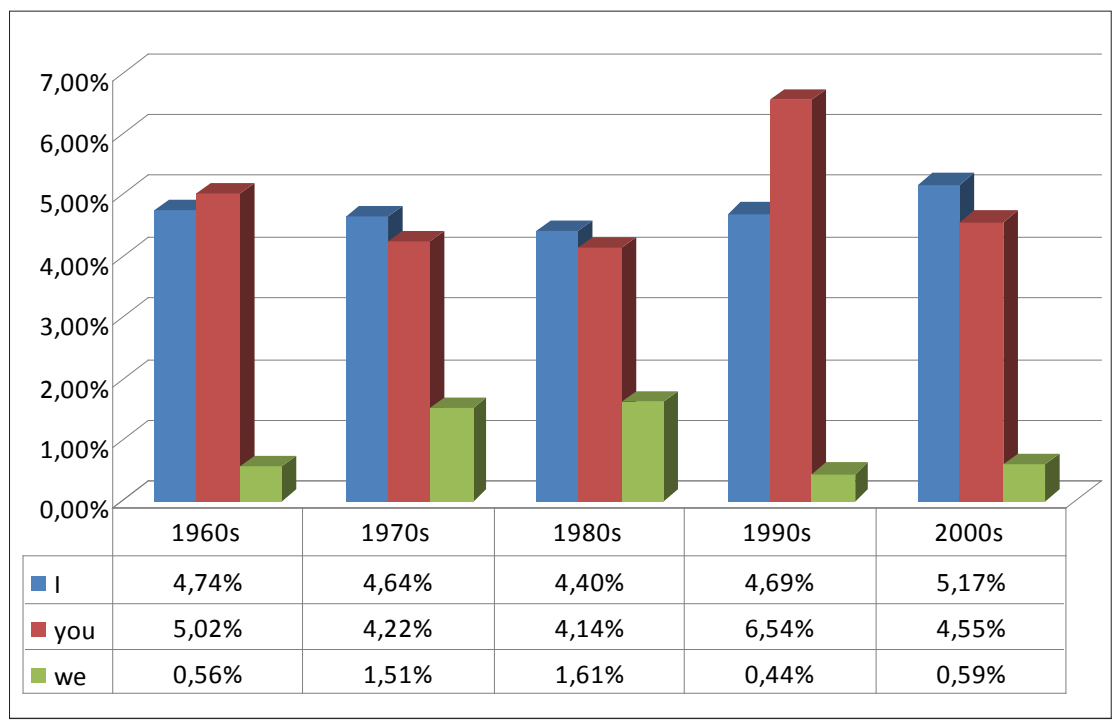

Figure 2. Percentages in the appearances of 'I', 'you', and 'we' in Pop music. 


\section{Speech Acts - The Problem}

Recognizing speech acts within the scope of lyrics was perhaps the most difficult task to tackle. Before attempting to see song lyrics in terms of speech acts, the first thing that should be done is investigate their context. In song lyrics, the elements comprising the context are blurred. After all, we are talking about a mass communication text which "is likely to be consumed in various sorts of places and at various times" (Fairclough, 1995: 36). It is also characterized by "one-sidedness" as "there is a sharp divide between the producers and the interpreters" (Fairclough: 2001: 41), since it is designed to be received by mass audiences.

Moreover, when talking about speech acts, one should initially consider the tripartite distinction of sentence types -the declarative, the interrogative and the imperative. This may not cover Searle's distinction of speech acts, but still "provide[s] us with an empirical base for constructing the common-sense or cognitive model of speech acts" (Croft 1994: 471). Lyons also seems to agree by arguing that these sentence-types constitute the three basic speech acts (1981: 251).

Of course, this should not light-heartedly be extended to the respective speech acts. These conventional markers may be successful at pointing towards a specific illocutionary force, the actual speech act, however, may not necessarily correspond to a grammatical indication or form.

At this point it should be mentioned that, even if one considers literary texts to be a development of ordinary language (Fabb 2010: 1230), one cannot ignore the fact that the language employed by the former is not actually doing things to the maximum of its illocutionary force, but rather it pretends to be doing things (acts as if). The speaker of fictional discourse "pretends to perform a series of illocutionary acts, normally of the representative type [...] without undertaking the commitments that are normally required" (Searle 1975: 325, 326). Fish also seems to agree that there is "a kind of discourse that is characterized by the suspension of the rules to which speech acts are normally held accountable" (1976: 1017). This can be the case for song lyrics as well, and this actually is what gives the audience the illusion of serious ${ }^{13}$ discourse, as Searle would put it.

Under these circumstances, it might seem meaningless to undertake the task of interpreting speech acts or investigating the use of politeness strategies in song lyrics, since the force of utterances is somehow lost in 'as-if' illocutionary performances, as the utterer is safe in terms of politeness in the sanctuary of fictional or literary discourse.

13 Searle makes a distinction between serious and nonserious literature not in a derogatory sense, but rather in the sense that if an author of a novel or a poem tells us "that it is raining outside, he isn't seriously committed to the view that it is at the time of writing actually raining outside" (1975: 321) 


\section{The Alternative - Sentence Types and Politeness Strategies}

Considering all the above, an alternative approach to the research presented itself; it is evident and undeniable that most of the sentences in the lyrics collected are declaratives; However, one cannot discern beyond the declaratives in the lyrics to interpret them as indirect speech acts, and in this sense, the two remaining sentence-types, namely imperative and interrogative sentences, as well as their frequency of appearance, took on the primary role in this research.

Compiling the interrogatives and imperatives for each corpus ${ }^{14}$ proved to be a tedious task, since the concordances software did not offer a relevant feature; therefore, it had to be done manually. The benefit to this however, was the option to exclude repetitions of the same sentence, given the recurrent nature of some lyrics.

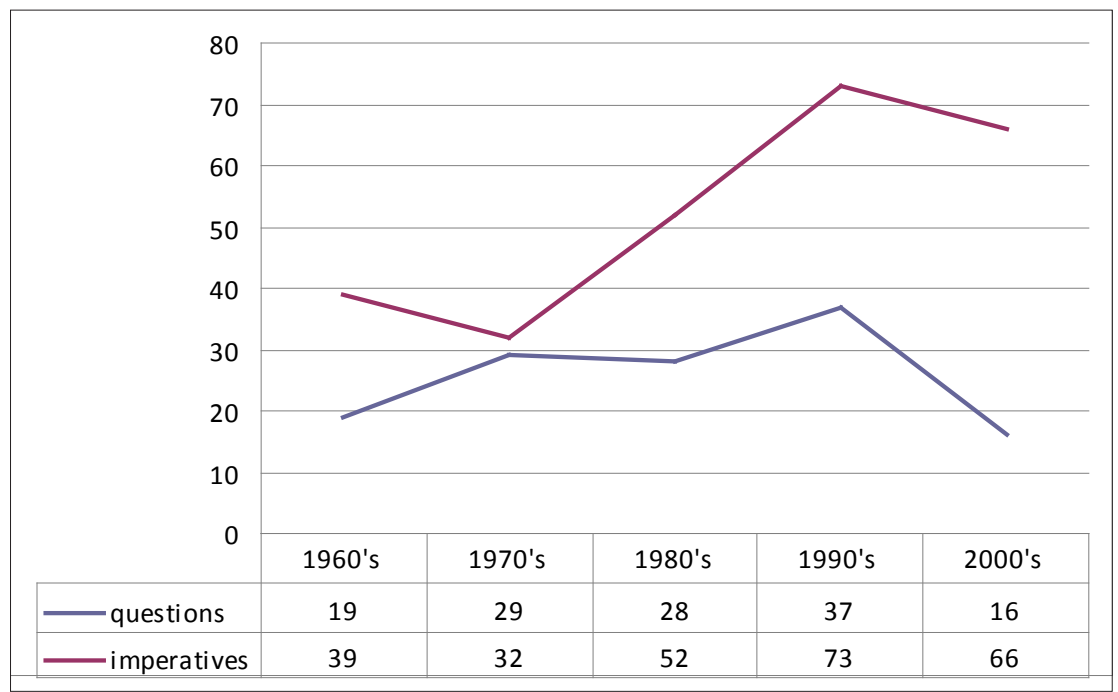

Figure 3. Distribution of interrogative and imperative sentences in Rock music

The results were indicative of an increasing tendency in using more imperatives in relation to an opposite trend in interrogatives. More specifically, in the rock music corpora, during the 1960 s the questions employed are half the number

14 The pop music corpora were not included in this part of the research, due to the sample's diversity consisting of new musical subgenres such as rap and hip hop, as mentioned earlier. 
of imperatives -19 and 39 respectively, whereas in 1970s this difference becomes quite small -29 over 32. In the 1980s however, the gap between the two becomes visible once again with 28 questions over 52 imperatives, and it gradually increases in the 1990 s -37 over 73 respectively - when, upon investigating the 2000's the imperatives are more than four times the number of questions -66 over 16.

The use of imperatives and questions in song lyrics offers a "sense of personal interaction" (Fowler, 1991: 65) in itself. The evident, however, preference towards employing imperatives may have implications regarding politeness strategies. Using the imperative generally gives the impression of imposing on the addressee, which may threaten their negative face ${ }^{15}$.

Brown and Levinson assert that "direct imperatives stand out as clear examples of bald-on-record usage" (1987: 95). This usage is employed for maximum efficiency in a communicative urgency, which can be also metaphorical when one is begging; this seems to agree also with Grice's Maxim of Manner regarding brevity of the contribution. (1989: 27). Imperatives can also be used in "pre-emptive invitations" including welcoming, farewells, and offers. (Brown and Levinson, 1987: 95-101) These two explanations, however, entail the assumptions that the addressee will translate this use as a politeness strategy, and that the speaker does not intend to threaten the face of the addressee. But consider the following examples taken from the corpora:

1. Save me from the nothing I've become. Bring me to life ${ }^{16}$

2. Give me your heart, make it real or else forget about it ${ }^{17}$

3. Welcome to this place, I'll show you everything ${ }^{18}$

4. Go drill your deserts - Go dig your graves. Then fill your mouth with all the money you will save ${ }^{19}$

5. Here we are now, entertain us ${ }^{20}$

6. Don't try to push your luck, just get out of my way ${ }^{21}$

15 Of course, imperatives employed in the addressee's interest should be excluded, since they operate as an "attempt to overcome H's reluctance to impose on S, by pretending that $\mathrm{S}$ has the power to force $\mathrm{H}$ to act" (Brown and Levinson, 1987: 229), and therefore contain no threat against the face of the addressee.

16 Bring me to life by Evanescence

17 Smooth performed by Santana and Rob Thomas

18 With arms wide open by The Creed

19 Psychosocial performed by Slipknot

20 Smells like teen spirit by Nirvana

21 Back in black performed by AC/DC 
Even without the help of contextual information, it can be inferred that examples (1) and (2) fall into the communicative urgency category, be it literal or metaphorical. The potentially face threatening act expressed with the imperative is performed without the use of the particle please and without any identity markers or certain address forms that may mitigate the threat (Brown and Levinson, 1987: 107-110). This intensifies the urgency expressed, but still, the lack of further redressive action weighs the scale towards a weightier FTA. The third example is obviously a welcoming, covering the second polite option Brown and Levinson present.

The three remaining examples are a bit problematic, since they cannot be explained in terms of politeness strategies.

Consider the calculus Brown and Levinson (1987) have suggested:

$$
W_{x}=D(S, H)+P(H, S)+R_{x}
$$

where $W_{x}$ is the value that measures the weightiness of the given act. It includes three variables, the social distance (D) between the speaker and the hearer, the relative power $(P)$ between the two and the absolute ranking ( $R$ ) of the imposition in the given situation. Brown and Levinson acknowledge that the variables at work here may be connected in more complex ways, they state however, that "all three dimensions $P, D$ and $R$ contribute to the seriousness of an FTA" (1987: 76).

By considering that two of the variables, $D$ and $R$ are constant, then the weight of the FTA would depend on the third one. Given that examples (4) to (6) constitute quite addressee-adversarial acts, it can be assumed that the speaker deems the relative power $(P)$ between him/her and the addressee to be quite high. In other words, the speaker does the FTA because of the power he/she may feel to have over the hearer. This, however, is only a subjective estimation on behalf of the hearer and may not actually correspond to reality; Still, the speaker goes on and performs the FTA apparently on the assumed power-be it physical, psychological or emotional- he/she has over the addressee.

Although this claim lacks sturdy grounding in a thoroughly systematic observation and analysis of the imperatives employed in lyrics that would unambiguously delineate their true illocutions, there is still clear evidence for positing the impolite use of the imperative; this pragmatic feature, too, seems to squarely fall in place with the previous results of pronominal occurrence concerning the ego-centricity projected in rock music. This, of course, does not constitute a generalised assumption that all the imperatives employed in the corpora are of this kind, but since their frequency increases dramatically over time, it is sensible to assume that this use is also extended.

Finally, both pop and rock corpora were processed in order to see the frequency of use of potential address terms that may convey in-group membership and 
therefore be employed as redressive action ${ }^{22}$ in politeness strategies. The results reveal once again that there is a decreasing trend in the use of such forms, which is clearly prominent in the 2000's, where there are only 4 instances of address forms in a corpus of 6404 word tokens - 3 instances of baby and 1 of darling-.

Overall, the only address form used consistently in both music genres and throughout the decades, is baby and babe. Apart from that, there are other terms employed for addressing the hearer in the rock music corpora, their occurrences, however, are represented by one-digit numbers scattered in each corpus.

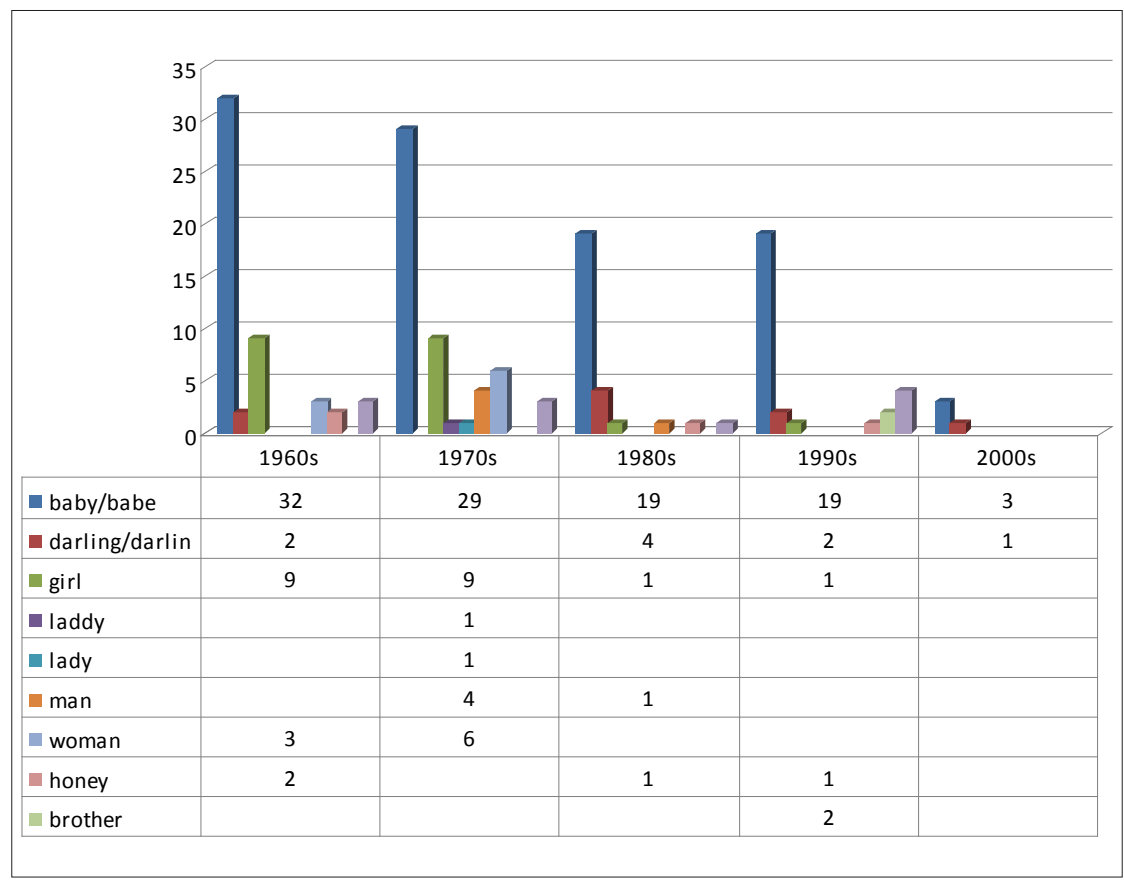

Figure 4. Distribution of address forms - and 'please' in the Rock music corpora.

During the 1960 s 48 such terms are estimated, 32 of which are of the word baby, whereas the 1970s follow the same pattern with 50 occurrences. In the 1980 s and the 1990s the decrease in the use of terms is obvious, since there are only 26 and 25 -respectively- overall occurrences, 19 of which are of the term baby, whereas in the 2000 s there are only 4 occurrences, 3 of the term baby and 1 of the term darling.

$\mathbf{2 2}$ The data were also studied manually in order to verify that it was indeed a case of addressing a speaker. 


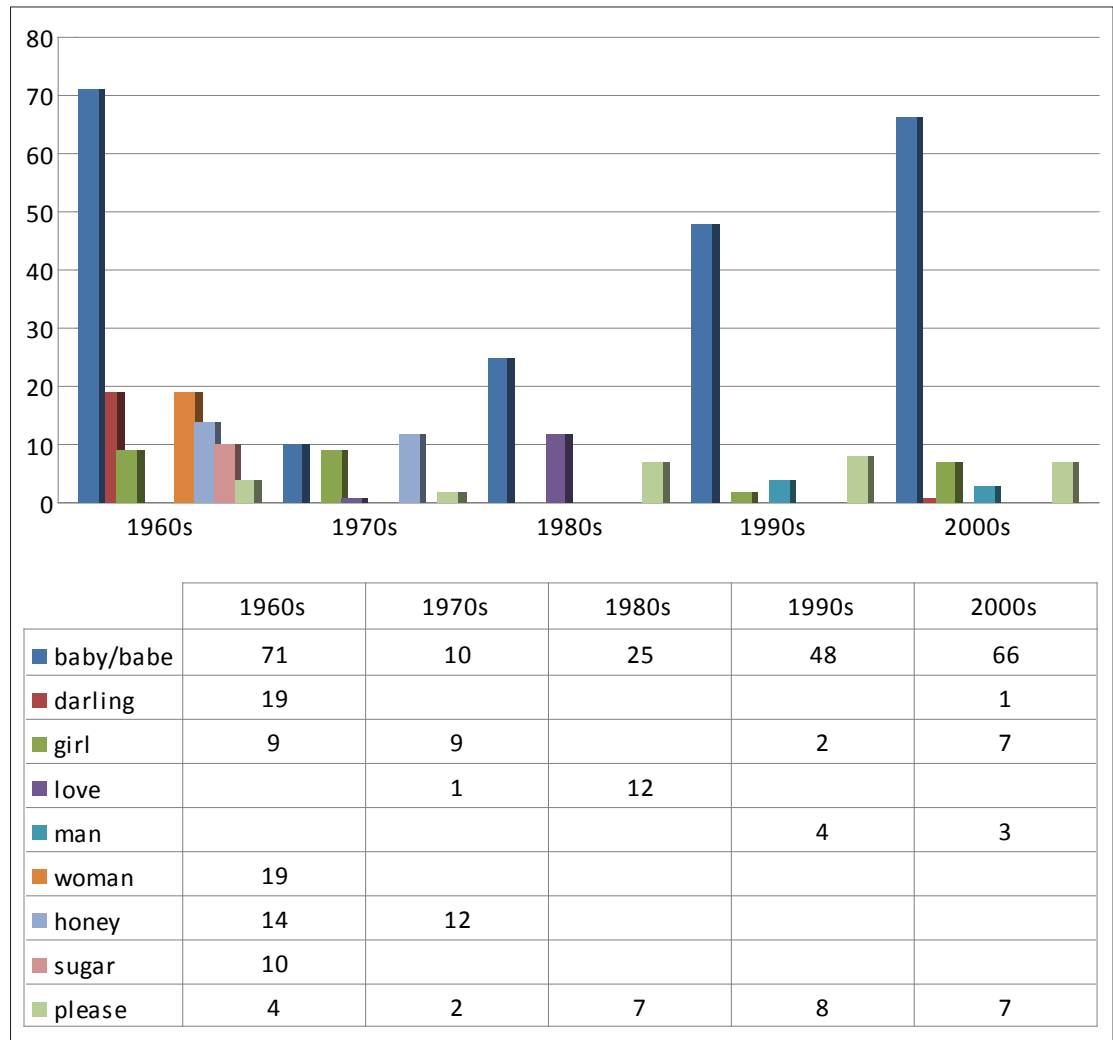

Figure 5. Distribution of address forms - and 'please'- in the Pop music corpora.

The pattern is different in the pop music corpora. The term baby is again systematically present in all decades; however, there doesn't seem to be a decrease in the term's occurrences. A sharp fall is observed during the 1970s (10 appearances) compared to 1960s (71 appearances), but since then the occurrences have been gradually increasing. This may be attributed once again to the nature of pop songs, focusing mainly on love and affection, which is expressed even in ordinary language with such endearment terms.

This gradual decline in the occurrences of such terms in rock music and their rarity in general, indicates that either employing such terms is not a common strategy in song lyrics or it is considered that there is neither need nor space for such terms. This second assumption seems to agree with what was suggested earlier considering the findings so far; lyrics in popular music are more assertive, the speaker is -or considers himself/herself to be- more powerful, and subsequently language becomes rather bald, without really worrying about civility, courtesy or politeness in the lyrics discourse. 
The mitigating particle please also seems to be absent in the corpora of both genres, which shows that the conventional politeness norms are not actually followed in song lyrics. This however, seems to be a general phenomenon as Lakoff observes:

One way in which conventional politeness is communicating is by taking a bit of extra time, saying that additional syllable or two that conveys that [...] attending to the human needs of the interlocutor comes first. But in America, we say, "Time is money." The removal of "please" merely instantiates that belief in a newly explicit way.

(Lakoff, 2005: 33-34)

In this sense, it can be ascertained that the pragmatic demeanour of song lyrics may in fact represent a general tendency towards being more terse and direct, and subsequently avoid the use of politeness strategies that might take up space and time while taking their toll on substance.

\section{Conclusion-Does the Song Remain the Same?}

The results regarding the rock music corpora suggest that there is indeed a pragmatic shift, implying that assertiveness is more prominent in song lyrics and that the projected power of the speaker over the assumed addressee is increasing leaving less room for politeness strategies.

Concerning the relation between rock and pop music, the findings seem to be less systematic. Pop music does not always follow the rock tendency discussed, mainly because of its diachronically constant content. This difference may be explained by means of an oxymoron. Pop music probably does not represent the pop culture of a time, at least to the same extent as rock music does. In this sense, rock is more pop than pop is.

To answer the original question posed as the title to this essay, no, the song does not remain the same. Not only does it develop in terms of musical styles and techniques, but also in terms of lyrics. There has to be an interchange between the lyrics and the people who listen to the lyrics and this interchange may reflect or even affect both sides in terms of language use.

However, there remains much work to be done regarding the joint areas of popular music -lyrics- and language use. The need for further research should be stressed; although there is a vast amount of literature on popular music, the pragmatic aspect of this genre has been somehow overlooked mainly due to the impediments discussed. 


\section{References}

Adorno, T. 2002. On Popular Music [with the assistance of George Simpson] (1941). In Essays on Music: Theodore W. Adorno; Selected with Introduction, Commentary and notes by Richard Leppert; New Translations by Susan H. Gillespie, 437-469. Berkeley and Los Angeles, California: University of California Press.

Androutsopoulos, J. and Scholz, A. 2002. On the recontextualization of Hip-Hop in European speech communities: A contrastive analysis of rap lyrics. Philologie im Netz (PhiN) (19), 1-42.

Brown, P. and Levinson, S.C. 1987 (1978). Politeness: Some Universals in Language Usage. Cambridge: Cambridge University Press.

Croft, W. 1994. Speech Act Classification, Language Typology and Cognition. In S.L. Tsohatzidis (Ed.), Foundations of Speech Act Theory. Philosophical and Linguistic Perspectives, 460-477. London and New York: Routlege.

Elliott, A. and Lemert, C.C. 2006. The new individualism: the emotional costs of globalization. Oxon: Routlege.

Fabb, N. 2010. Is literary language a development of ordinary language? Lingua 120 (5), 1219-1232.

Fairclough, N. 1995. Media Discourse. London: Edward Arnold.

Fairclough, N. 2001. Language and Power (2nd ed.). London: Longman.

Fish, S. E. 1976. How to do things with Austin and Searle: Speech Act Theory and Literary Criticism. MLN (Modern Language Notes) , 91 (5), 983-1025. 
Fowler, R. 1991. Language in the News: Discourse and Ideology in the Press. New York: Routlege.

Frith, S. 1993. Popular Music and the Local State. In T. Bennett, S. Frith, L. Grossberg, ]. Shepherd and G. Turner (Eds.), Rock and Popular Music: Politics, Policies, Institutions, 14-24. Routlege.

Grice, P.H. 1989. Meaning. In P.H. Grice, Studies in the ways of words, 213-223. Cambridge, Mass.: Harvard University Press.

Grossberg, L. 1993. The Framing of Rock: Rock and the New Conservatism. In T. Bennett, S. Frith, L. Grossberg, J. Shepherd and G. Turner (Eds.), Rock and Popular Music: Politics, Policies, Institutions, 193-209. Routlege.

Kimbel, T.M. and Protivnak, J.J. 2010. For Those About to Rock (With Your High School Students), We Salute You: School Counselors Using Music Interventions. Journal ofCreativity in Mental Health, 5 (1), 25 - 38.

Knobloch-Westerwick, S., Musto, P. and Shaw, K. 2008. Rebellion in the TopMusic Charts: Defiant Messages in Rap/Hip-Hop and Rock Music 1993 and 2003. Journal of Media Psychology, 20 (1), 15-23.

Kuhn, E.D. 1999. 'I just want to make love to you' - Seductive strategies in blues lyrics. Journal of Pragmatics (31), 525-534.

Lakoff, R.T. 2005. Civility and its Discontents: or, Getting in your Face. In R.T. Lakoff and S. Ide (Eds.), Broadening the Horizon of Linguistic Politeness, 23-44. Amsterdam and Philadelphia: John Benjamins Publishing Company.

Lyons, J. 1981 (1995). Linguistic Semantics: An Introduction. Cambridge University Press.

Mooney, H.F. 1954. Songs, Singers and Society, 1890-1954. American Quarterly, $6(3), 221-232$.

Paquette, K.R. and Rieg, S.A. 2008. Using Music to Support the Literacy Development of Young English Language Learners. Early Childhood Educ Journal (36), 227-232.

Pennycook, A. 2003. Global Englishes, Rip Slyme, and performativity. Journal of Sociolinguistics, 7 (4), 513-533. 
Pettijohn, T.F. and Sacco, D.F. 2009. The Language of Lyrics : An Analysis of Popular Billboard Songs Across Conditions of Social and Economic Threat. Journal of Language and Social Psychology, 297-311.

Quirk, R., Greenbaum, S., Leech, G. and Svartnik, J. 1972. A Grammar of Contemporary English. London: Longman.

Robinson, T.O., Weaver, J.B. and Zillmann, D. 1996. Exploring the Relation between Personality and the Appreciation of Rock Music. Psychological Reports (78), 259-269.

Rutten, P. 1993. Popular Music Policy: a Contested Area - The Dutch Experience. In T. Bennett, S. Frith, L. Grossberg, J. Shepherd and G. Turner (Eds.), Rock and Popular Music: Politics, Policies, Institutions, 37-51. London and New York: Routlege.

Searle, J.R. 1975. The Logical Status of Fictional Discourse. NLH (New Literary History), IV, 319-332.

Singer, M. 1989. Pronouns, Persons and the Semiotic Self. In B. Lee and G. Urban (Eds.), Semiotics, Self and Society, 229-298. Berlin: Mouton de Gruyter.

Twenge, J.M. 2007. Generation Me: Why Today's Young Americans Are More Confident, Assertive, Entitled--and More Miserable Than Ever Before. New York: Free Press.

Wiehman, D. and Fuhs, S. 2006. Corpus Linguistics Resources: Concordancing software. Corpus Linguistics and Linguistic Theory (2-1), 109-130. 
Major Trends in Theoretical and Applied Linguistics 